\title{
Detecting Activity in Olfactory Bulb Glomeruli with Astrocyte Recording
}

\author{
Didier De Saint Jan and Gary L. Westbrook \\ Vollum Institute, Oregon Health and Sciences University, Portland, Oregon 97239
}

\begin{abstract}
In the olfactory bulb, axons of olfactory sensory neurons (OSNs) expressing the same olfactory receptor converge on specific glomeruli. These afferents form axodendritic synapses with mitral/tufted and periglomerular cell dendrites, whereas the dendrites of mitral/tufted cells and periglomerular interneurons form dendrodendritic synapses. The two types of intraglomerular synapses appear to be spatially isolated in subcompartments delineated by astrocyte processes. Because each astrocyte sends processes into a single glomerulus, we used astrocyte recording as an intraglomerular detector of neuronal activity. In glomerular astrocytes, a single shock in the olfactory nerve layer evoked a prolonged inward current, the major part of which was attributable to a barium-sensitive potassium current. The $\mathrm{K}^{+}$ current closely reflected the time course of depolarization of mitral/tufted cells, indicating that $\mathrm{K}^{+}$accumulation mainly reflects the activity of mitral/tufted cells. The astrocyte $\mathrm{K}^{+}$current was dependent on AMPA and NMDA receptors in mitral/tufted cells as well as on a previously undescribed metabotropic glutamate receptor 1 component. Block of the $\mathrm{K}^{+}$current with barium unmasked a synaptic glutamate transporter current. Perhaps surprisingly, the transporter current had components caused by glutamate released at both olfactory nerve terminals and mitral/tufted cell dendrites. The time course of the transporter currents suggested that rapid synchronous glutamate release at OSN terminals triggers asynchronous glutamate release from mitral/tufted cells. Glomerular astrocyte recording provides a sensitive means to examine functional compartmentalization within and between olfactory bulb glomeruli.
\end{abstract}

Key words: olfactory bulb; glomerulus; astrocytes; $\mathrm{K}^{+}$buffering; glutamate transporters; mGluRs

\section{Introduction}

Activation of each of the $\sim 500$ odorant receptors produces discrete activation of glomeruli in the olfactory bulb, thereby creating a spatial map (Ressler et al., 1994; Vassar et al., 1994; Mombaerts et al., 1996; Buck, 2000). Because mitral cells project their primary dendrites to a single glomerulus, the transformation of the spatial map into an odor code can be influenced by local processing within the glomerular layer. Glomeruli are thus often considered as functional units (Schoppa and Urban, 2003). Although the ultrastructural organization of a glomerulus has been well documented (Kosaka et al., 1998), the cascade of intraglomerular events triggered by olfactory inputs has been more difficult to explore (Schoppa and Urban, 2003). Neuronal recording is the usual approach to such questions within a neural circuit, but astrocytes also can be used as surrogate detectors of neuronal activity (Orkand et al., 1966; Bergles and Jahr, 1997).

Glomeruli are a complex mix of glial and neuronal elements. Astrocyte cell bodies form an almost complete envelope around a glomerulus and send processes into the central neuropil (Valverde and Lopez-Mascaraque, 1991; Bailey and Shipley, 1993; Chao et al., 1997). Along with periglomerular neurons,

Received Dec. 10, 2004; revised Feb. 7, 2005; accepted Feb. 7, 2005.

This work was supported by the Human Frontier Science Program (LT00283/2002-C; D.D.S.J.) and by the National Institutes of Health (NS 26494; G.L.W.). We thank present and former members of the Westbrook laboratory for their support and valuable suggestions and AeSoon Bensen for technical assistance.

Correspondence should be addressed to Didier De Saint Jan, Vollum Institute, Oregon Health and Sciences University, 3181 Southwest Sam Jackson Park Road, Portland, OR 97201. E-mail: desaintj@ohsu.edu.

D0I:10.1523/JNEUROSCI.5042-04.2005

Copyright $\odot 2005$ Society for Neuroscience $\quad$ 0270-6474/05/252917-08\$15.00/0 astrocytes encapsulate a tightly packed network of olfactory neuron terminals, apical dendrites of mitral and tufted cells, dendrites of local periglomerular interneurons, astrocyte processes, and vasculature (Pinching and Powell, 1971). In vitro, extracellular potassium increases within glomeruli after afferent stimulation (Jahr and Nicoll, 1981; Khayari et al., 1988; Friedrich and Korsching, 1998). Glial barriers that remove extracellular potassium (Amédée et al., 1997; Kofuji and Newman, 2004) may prevent the spread of activity (Goriely et al., 2002).

Within a glomerulus, excitatory axodendritic synapses are located in so-called "axonal" compartments that are relatively devoid of glial processes. In contrast, dendrodendritic synapses in "dendritic" compartments are often encapsulated by glial processes (Chao et al., 1997; Kosaka et al., 1997; Kasowski et al., 1999; Kim and Greer, 2000). Glomerular astrocytes express a high level of glutamate transporters (GluTs) (Utsumi et al., 2001). Thus, their distribution at the interface between subcompartments could prevent cross talk between axodendritic and dendrodendritic synapses.

We examined intraglomerular activity using whole-cell recordings from astrocytes. We used glial $\mathrm{K}^{+}$currents (Orkand et al., 1966) as a detector of the overall intraglomerular neuronal activity and glutamate transporter currents (Bergles and Jahr, 1997) as detectors of synaptic glutamate release within a glomerulus.

\section{Materials and Methods}

Slice preparation. Olfactory bulbs were prepared according to the procedure described by Schoppa et al. (1998). Animal use was approved by the 
Institutional Animal Care and Use Committee of the Oregon Health and Sciences University. Briefly, postnatal day 14 (P14) to P20 Sprague Dawley rats or P14-P35 GFAP-hGFP-S65T mice (The Jackson Laboratory, Bar Harbor, ME) (Zhuo et al., 1997) were anesthetized with halothane and then decapitated. The bulbs were carefully removed, and 250- to $350-\mu \mathrm{m}$-thick horizontal slices were cut on a vibratome (VT1000S; Leica, Nussloch, Germany). During dissection and slicing, tissues were submerged in an ice-cold solution containing (in mM): $125 \mathrm{NaCl}, 25$ $\mathrm{NaHCO}_{3}, 2.5 \mathrm{KCl}, 1.25 \mathrm{NaH}_{2} \mathrm{PO}_{4}, 2 \mathrm{MgCl}_{2}, 0.5 \mathrm{CaCl}_{2}$, and 25 dextrose. This solution was continuously bubbled with a mixture of $95 \% \mathrm{O}_{2}$ and $5 \% \mathrm{CO}_{2}$ to maintain the $\mathrm{pH}$ at 7.4. The osmolarity was adjusted to 290 mOsm. Once cut, slices were maintained in the same solution at $37^{\circ} \mathrm{C}$ for $40 \mathrm{~min}$ and then at room temperature for at least $30 \mathrm{~min}$ before experiments.

Electrophysiology. A slice was transferred in a recording chamber and visualized with an upright microscope (BX51WI; Olympus Optical, Tokyo, Japan) using infrared differential interference contrast videomicroscopy. The slice was continuously perfused with a standard external solution similar to the slicing solution except for the concentrations of $\mathrm{MgCl}_{2}$ $(1 \mathrm{~mm})$ and $\mathrm{CaCl}_{2}(2 \mathrm{~mm})$. Unless indicated, experiments were performed at $33-36^{\circ} \mathrm{C}$. Whole-cell voltage-clamp recordings in visually identified or fluorescent-labeled astrocytes and current-clamp recordings from mitral/tufted cells were obtained using 3-7 M $\Omega$ patch pipettes filled with an internal solution containing (in $\mathrm{mM}$ ): $125 \mathrm{~K}$-gluconate, 2 $\mathrm{CaCl}_{2}, 2 \mathrm{MgCl}_{2}, 1$ or 10 EGTA, $2 \mathrm{Na}$-ATP, 0.5 Na-GTP, and 10 HEPES. We used an intracellular solution containing barium to record glutamate transporter currents from astrocytes (Matsui and Jahr, 2003). It contained (in mM): $125 \mathrm{~K}$-gluconate, 10 HEDTA, $3 \mathrm{BaCl}, 2 \mathrm{Na}$-ATP, 0.5 Na-ATP, and 10 HEPES. Currents were recorded with a Multiclamp 700A amplifier (Axon Instruments, Foster City, CA). Data were acquired using Axograph 4.6 or 4.9 software (Axon Instruments), digitized at 10 $\mathrm{kHz}$, and filtered at $1-2 \mathrm{kHz}$. Olfactory sensory neurons (OSNs) were stimulated using a platinum/iridium bipolar electrode (Frederick Haer Co., Bowdoinham, ME) or a patch pipette filled with external solution connected to a DS2A-Mk.II isolated stimulator (Digitimer, Hertfordshire, UK). The electrical stimulus was $100 \mu$ s with an intensity of 1-100 $\mathrm{V}$. Each stimulation was preceded by a $2 \mathrm{mV}$ depolarizing pulse to monitor the access resistance. Rundown of evoked astrocyte responses sometimes occurred during an experiment accompanied by a decrease in access resistance. Cells that showed a $>20 \%$ change in access resistance were discarded. For analysis, $4-10$ consecutive traces were averaged. Results are expressed as mean \pm SE. $p$ values were derived from paired $t$ tests to assess statistical significance.

Immunohistochemistry. To examine the distribution of astrocytes, olfactory bulbs from GFAP-green fluorescent protein (GFP) mice were fixed in $4 \%$ paraformaldehyde in PBS for $48 \mathrm{~h}$ at $4^{\circ} \mathrm{C}$ and cut in $50-\mu \mathrm{m}-$ thick horizontal sections using a microtome. After washout with PBS, fixed slices were incubated overnight at $4^{\circ} \mathrm{C}$ in a permeabilizing PBS solution (0.4\% Triton X-100 plus 1\% BSA) containing 1:1000 Alexa Fluor 488-labeled rabbit anti-GFP antibody. Sections were then washed three times with PBS before mounting with ProLong Antifade. For cell characterization, biocytin $(0.2 \%)$ was included in the recording pipette solution. Slices were fixed in $4 \%$ paraformaldehyde overnight, washed three times, and incubated in a permeabilizing solution containing cyanine 5-conjugated streptavidin $(1 \mu \mathrm{g} / \mathrm{ml}$; Jackson ImmunoResearch, West Grove, PA) for $1 \mathrm{~d}$. After three washes with PBS, propidium iodide ( $5 \mu \mathrm{g} / \mathrm{ml} ; 30 \mathrm{~min}$ ) was added as a nuclear stain. Sections were washed three times before mounting. Labeled cells were visualized with a confocal microscope. Unless indicated, all reagents were purchased from Molecular Probes (Eugene, OR).

Chemicals. Drugs were diluted in the standard external solution, except for cadmium, which was diluted in a phosphate-free external solution containing (in mM): $135 \mathrm{NaCl}, 5 \mathrm{NaHCO}_{3}, 5$ HEPES, $2.5 \mathrm{KCl}, 1$ $\mathrm{MgCl}_{2}, 2 \mathrm{CaCl}_{2}$, and 25 dextrose. Dihydrokainic acid (DHK), DL-threo$\beta$-benzyloxyaspartic acid (TBOA), DL-2-amino-5-phosphonopentanoic acid (AP-5), 6-nitro-7-sulfamoylbenzo[f]quinoxaline-2,3-dione (NBQX), and (S)-(+)- $\alpha$-amino-4-carboxy-2-methylbenzeneacetic acid (LY367385) were purchased from Tocris (Ellisville, MO). Threo- $\beta$-hydroxyaspartic
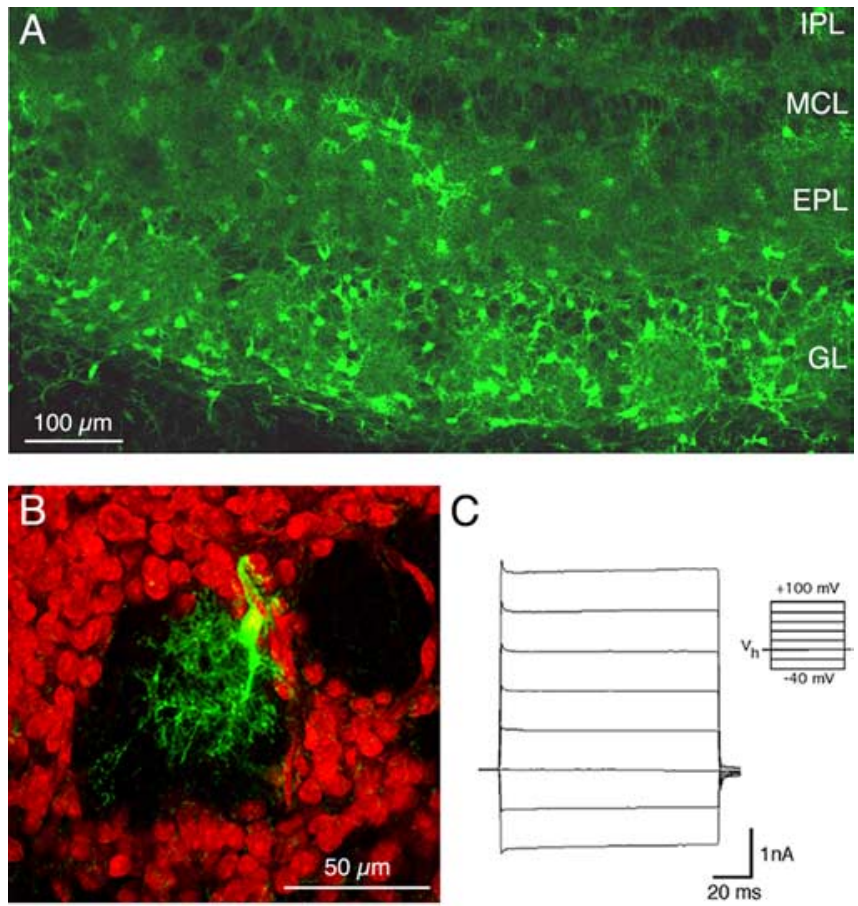

Figure 1. Astrocyte identification in olfactory bulb slices. $A$, Astrocytes in an olfactory bulb slice from a GFAP-GFP transgenic mouse were easily identified around glomeruli. For better definition of glial processes, fluorescence of the astrocytes was enhanced by postfixation labeling with an anti-GFP antibody coupled to Alexa Fluor 488. IPL, Internal plexiform layer; MCL, mitral cell layer; EPL, external plexiform layer; GL, glomerular layer. $\boldsymbol{B}, \mathrm{A}$ glomerular astrocyte (green) was filled with biocytin and visualized with a confocal microscope. Note that the astrocyte processes are confined to a single glomerulus. The glomerulus is delimited by periglomerular cells labeled with propidium iodide (red). C, The glomerular astrocyte shown in $\boldsymbol{B}$ had a linear current-voltage relationship, typical of astrocytes ( $20 \mathrm{mV}$ steps, from -40 to $+100 \mathrm{mV}$; $V_{\mathrm{h}}=$ $-80 \mathrm{mV})$.

acid (THA), cadmium chloride, and barium chloride were purchased from Sigma (St. Louis, MO).

\section{Results}

\section{Identification of glomerular astrocytes}

We made whole-cell voltage-clamp recordings from astrocytes in olfactory bulb glomeruli. In slices from rat brain, astrocyte cell bodies were visually identified at the inner edge of the ring of cell bodies surrounding a glomerulus or within the neuropil of a glomerulus. Because of their small number ( $\sim 7 \%$ of juxtaglomerular cells are astrocytes) (Chao et al., 1997) and their resemblance to some periglomerular neurons, identification was difficult. Therefore, we also used transgenic mice expressing GFP under the control of a glial-specific GFAP promoter (GFAPhGFP-S65T) (Zhuo et al., 1997). Fluorescent astrocytes were especially numerous in the glomerular layer, and several could be seen around and within a single glomerulus (Fig. $1 \mathrm{~A}$ ). Consistent with previous descriptions (Bushong et al., 2002), fluorescent astrocytes exhibited dense spongiform ramifications extending from major processes. In both preparations, cells visualized with biocytin had a small diameter $(\sim 5-10 \mu \mathrm{m})$ and, as reported previously (Bailey and Shipley, 1993), projected processes into the core of a single glomerulus (Fig. $1 B$ ). Several cell bodies often were labeled when a single astrocyte was filled with biocytin, consistent with gap junction coupling between adjacent astrocytes (data not shown). Astrocytes had typical electrical properties, including a low input resistance $(19.1 \pm 1.7 \mathrm{M} \Omega, n=30$ cells in rats; $12.4 \pm 0.6 \mathrm{M} \Omega, n=41$ cells in mice), a negative resting 



Figure 2. The astrocyte response is composed of a potassium current and a glutamate transporter current. $A, O S N$ afferents were stimulated with a bipolar electrode or a patch pipette in the olfactory nerve layer. In voltage-clamp recordings in glomerular astrocytes (AS), stimulation evoked inward currents that increased with the stimulation intensity (right). $\mathrm{MC}$, Mitral cell; PG, periglomerular cells. $\boldsymbol{B}$, Extracellular perfusion of the potassium channel blocker Ba ${ }^{2+}(200 \mu \mathrm{M})$ blocked the majority of the evoked current in a voltage-clamped astrocyte. However, a fast $\mathrm{Ba}^{2+}$-insensitive current remained (gray box). $\boldsymbol{C}$, Expanded view of the traces in the gray boxin $\boldsymbol{B}$. The $\mathrm{Ba}^{2+}$-insensitive current was blocked by the glutamate transporter antagonist TBOA $(50 \mu \mathrm{M})$.

potential (usually more negative than $-80 \mathrm{mV}$ ), and a quasilinear $I-V$ relationship (Fig. $1 C$ ).

\section{The astrocyte response has two components}

As illustrated in Figure $2 \mathrm{~A}$, a brief electrical stimulation (100 $\mu \mathrm{s}$, $1-100 \mathrm{~V}$ ) of the olfactory nerve layer elicited a slowly decaying inward current with an amplitude and duration that increased with stimulus strength. The evoked current had a half-width of $1108 \pm 154 \mathrm{~ms}$ and an amplitude of $232 \pm 20 \mathrm{pA}$ in rats $(n=27$; stimulus, $49.4 \pm 5.5 \mathrm{~V})$. In mice, the half-width was $1049 \pm 156$ $\mathrm{ms}$ and the amplitude was $384 \pm 33 \mathrm{pA}(n=16$; stimulus, $59.4 \pm$ $7.9 \mathrm{~V})$.

Bath application of barium $(100-200 \mu \mathrm{M})$ inhibited the majority of the inward current $(82 \pm 3 \%$ charge reduction; $n=11$ ) (Fig. $2 \mathrm{~B}$ ). At this concentration, $\mathrm{Ba}^{2+}$ effectively blocks inward rectifier $\mathrm{K}^{+}$channels (IRKs) that are highly expressed in glial cells (Newman, 1993). IRKs are thought to be involved in the spatial buffering of $\mathrm{K}^{+}$released in the extracellular space during neuronal activity (Karwoski et al., 1989; Newman, 1993; Amédée et al., 1997; Kofuji and Newman, 2004). Because $\mathrm{K}^{+}$accumulates in the glomerular layer after OSN stimulation (Jahr and Nicoll, 1981; Khayari et al., 1988; Friedrich and Korsching, 1998), the $\mathrm{Ba}^{2+}$ sensitive component is consistent with IRK-dependant current in response to extracellular $\mathrm{K}^{+}$accumulation.

However, a fast transient inward current remained in the presence of $\mathrm{Ba}^{2+}$ (Fig. 2B,C). Subsequent addition of the nonselective GluT inhibitor TBOA $(50-100 \mu \mathrm{M})$ inhibited this residual current ( $84 \pm 1.8 \%$ peak reduction; $n=17$ ), thus identifying it as a synaptically activated glutamate transporter current. In rat slices, the transporter current had a mean amplitude of $128 \pm 20$ $\mathrm{pA}$ and a mean $10-90 \%$ rise time of $5.2 \pm 0.3 \mathrm{~ms}(n=20)$. In 19 of 20 cells, the decay was well fitted with a single exponential with

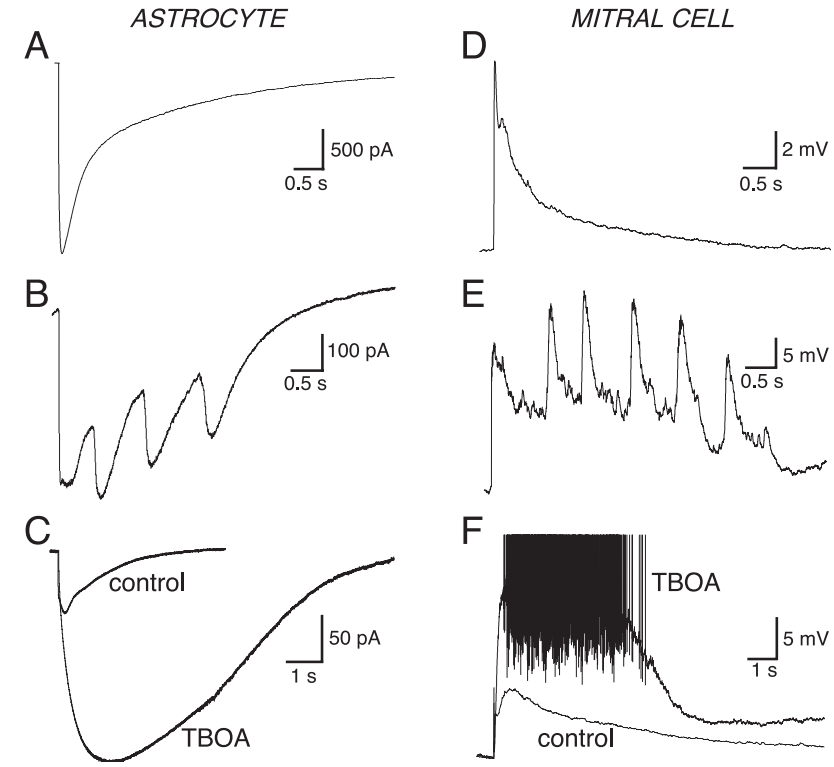

Figure 3. Comparison of astrocyte and mitral cell responses evoked by a single electrical stimulation of the olfactory nerve afferents. $A, D, A$ typical long-lasting current evoked in an astrocyte by stimulation in the olfactory nerve layer had a time course similar to the depolarization of mitral cells evoked by the same stimulation (right). $\boldsymbol{B}, \boldsymbol{E}$, Stronger stimulation evoked slow oscillating currents $(1-2 \mathrm{~Hz})$ in astrocytes in rat brain slices, again similar to the depolarization observed in mitral cells (right). C, Bath application of the glutamate transporter antagonist TBOA $(100 \mu \mathrm{m})$ enhanced both the evoked astrocyte current as well as the mitral cell EPSP leading to generation of action potential firing (right).

a time constant of $26 \pm 1 \mathrm{~ms}$. In mice, the amplitude of the transporter current was $151 \pm 30 \mathrm{pA}$ with a $10-90 \%$ rise time of $3.9 \pm 0.2 \mathrm{~ms}$ and a decay time constant of $16 \pm 0.8 \mathrm{~ms}(n=18)$. DHK (300 $\mu \mathrm{M})$, a specific blocker of GLT-1 (Bridges et al., 1999), reduced the amplitude of the GluT current by $35 \pm 5 \%(n=5$; data not shown), indicating that both GLAST (the other glial glutamate transporter) and GLT-1 participate in glutamate clearance. These results indicate that olfactory nerve stimulation evokes a two-component response in glomerular astrocytes: a large $\mathrm{K}^{+}$current and a smaller and faster glutamate transporter current.

\section{The slow component reflects mitral/tufted cell activity}

It has been suggested that most of the $\mathrm{K}^{+}$released in glomeruli after olfactory nerve stimulation originates from postsynaptic spiking cells (Jahr and Nicoll, 1981; Khayari et al., 1988). Although mitral/tufted cells and periglomerular neurons could potentially contribute to $\mathrm{K}^{+}$accumulation and thus to the astrocyte response, the slow component of the astrocyte response closely matched the time course of depolarizations evoked in mitral/ tufted cells (Fig. 3). Olfactory nerve stimulation elicited EPSPs in mitral or in tufted cells that also lasted several seconds (Fig. 3D) (see also Chen and Shepherd, 1997; Carlson et al., 2000) and could be slowly oscillating (Fig. 3E) (Schoppa and Westbrook, 2001). Very similar oscillations were evoked in astrocytes $(n=4)$ (Fig. 3B). Furthermore, potentiation of the mitral cell EPSP by GluT blockers also increased the amplitude and duration of the astrocyte response (Fig. 3C,F). The total charge carried by the astrocyte current was increased $13 \pm 2.2$-fold by TBOA $(100 \mu \mathrm{M}$; $n=4$ ) and $9 \pm 1.7$-fold by the competitive GluT antagonist THA (300 $\mu \mathrm{M} ; n=3)$.

If the $\mathrm{K}^{+}$component of the astrocyte response requires electrical activity in postsynaptic mitral/tufted cells, then it should be 
inhibited by blockers of synaptic transmission. Indeed, we found that cadmium, a broad-spectrum calcium channel blocker, greatly reduced the astrocyte response $(88 \pm 0.7 \%$ charge reduction; $n=4)$ (Fig. $4 A, D)$. These data also suggest that olfactory nerve terminals release only a small fraction of the $\mathrm{K}^{+}$detected by glomerular astrocytes. Similarly, postsynaptic inhibition of AMPA and NMDA receptors on mitral/tufted cells with NBQX $(20 \mu \mathrm{M})$ and AP-5 $(150 \mu \mathrm{M})$ also reduced the response $(80.3 \pm 1.7 \%$ reduction of the charge; $n=7$ ) (Fig. $4 B, D$ ). Hence the $\mathrm{K}^{+}$ component of the astrocyte response essentially mirrors activity in mitral/tufted cells.

\section{Astrocytes also detect a metabotropic glutamate receptor 1-mediated EPSP evoked in mitral or tufted cells}

Previous studies have suggested that afferent activation of mitral cells is completely blocked by AP-5 and NBQX (Chen and Shepherd, 1997; Carlson et al., 2000; Schoppa and Westbrook, 2001). However, inhibition of the astrocyte response by AP-5 plus NBQX was significantly less than inhibition by cadmium (Fig. $4 D$ ), suggesting the presence of an additional synaptic component. The kinetics of the currents in the two conditions were also different (Fig. 4C). The $\mathrm{Cd}^{2+}$ resistant current was slowly activating and slowly decaying, whereas the astrocyte response in the presence of AP-5 and NBQX included a fast TBOA-sensitive transporter current (see Fig. 6) followed by a long-lasting component that peaked $\sim 200$ $\mathrm{ms}$ after the stimulus. This slow component increased in amplitude and duration as a function of the stimulus strength (data not shown) and was reduced by the metabotropic glutamate receptor 1 (mGluR1)-selective antagonist LY367385 (50 $\mu \mathrm{M})$ (Fig. 4B). Block of all three types of glutamate receptors reduced the astrocyte response to the same extent as $\mathrm{Cd}^{2+}$ (86 $\pm 1.7 \%$ reduction; $n=8$ ) (Fig. 4D).

Glomerular astrocytes do not express mGluR1 (van den Pol, 1995). In contrast, mGluR1 is highly expressed in mitral and tufted cells, especially in apical dendrites within glomeruli (van den Pol, 1995). Thus, astrocytes detect a previously unreported mGluR1-mediated EPSP in mitral and tufted cells. To test this hypothesis, we recorded mitral or tufted cell EPSPs evoked by olfactory nerve stimulation (Fig. 5A). As reported by others (Chen and Shepherd, 1997; Carlson et al., 2000; Schoppa and Westbrook, 2001), mitral/tufted cell EPSPs were usually fully blocked by AP-5 plus NBQX ( $94 \pm 1.7 \%$ charge reduction; $n=$ 12 cells in mice). In some cells however, a small and slow EPSP remained in the presence of AP-5 and NBQX (Fig. 5A). This slow potential was blocked by LY367385 (Fig. 5A) and enhanced by TBOA (Fig. 5B). In cells that did not exhibit any residual depolarization in the presence of AP-5 and NBQX, adding TBOA or increasing stimulation was usually sufficient to reveal an mGluR1-mediated EPSP (data not shown). Thus, an mGluR1 response could be generated in mitral/tufted cells with only a single shock. This is in contrast to the mGluR postsynaptic response in neurons in other pathways, for which trains of stimuli are usually required (Anwyl, 1999).
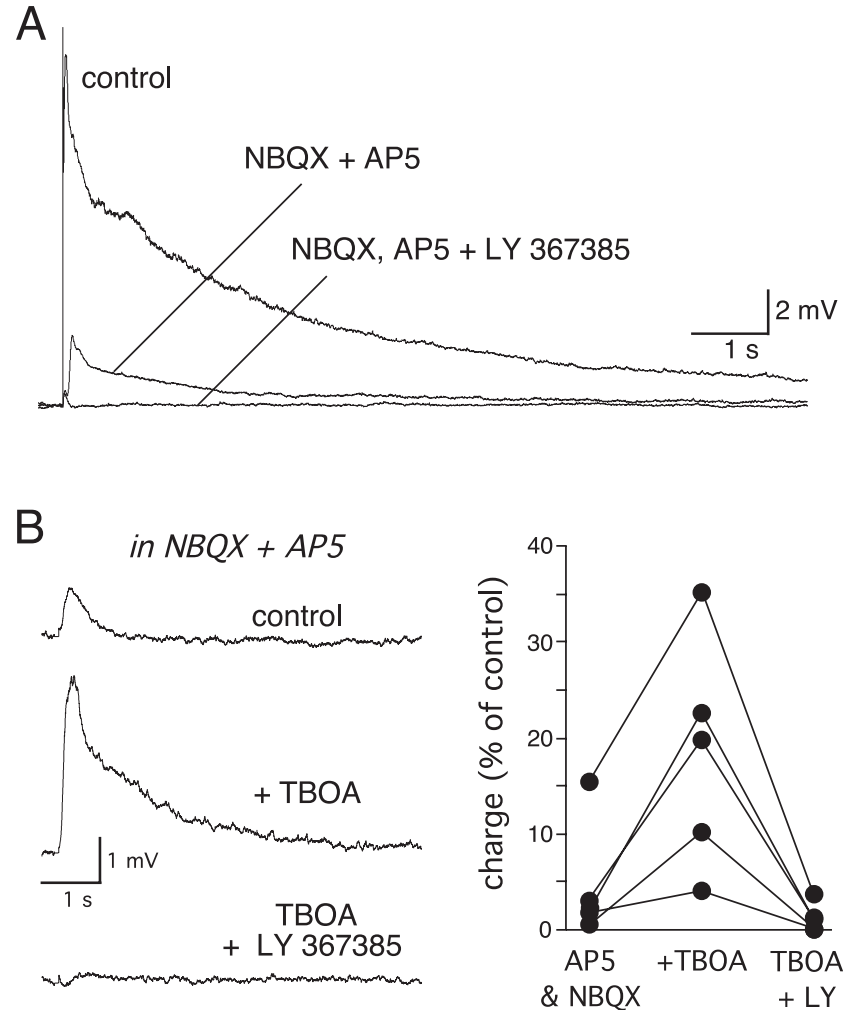

Figure 5. Olfactory nerve stimulation generates an mGluR1-mediated EPSP in mitral or tufted cells. $\boldsymbol{A}$, In mitral/tufted cells, stimulation of olfactory afferents evoked a large EPSP that was partially blocked by AP- $5(150 \mu \mathrm{M})$ and NBQX $(20 \mu \mathrm{m})$. The remaining current was blocked by the mGluR1 antagonist LY367385 (25-50 $\mu \mathrm{M})$. B , The mGluR1-mediated EPSP was potentiated by TBOA $(50 \mu \mathrm{M})$, a blocker of glutamate transporters. LY367385 completely blocked the facilitated mGluR1 EPSP. The response in five neurons is plotted as a percentage of the control EPSP and is shown to the right. LY, LY367385. 

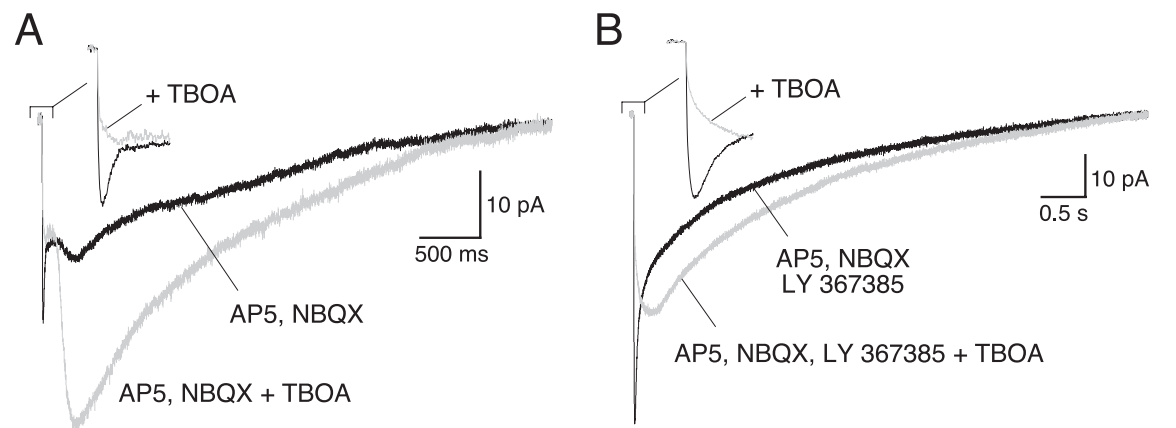

AP5, NBQX, LY $367385+$ TBOA
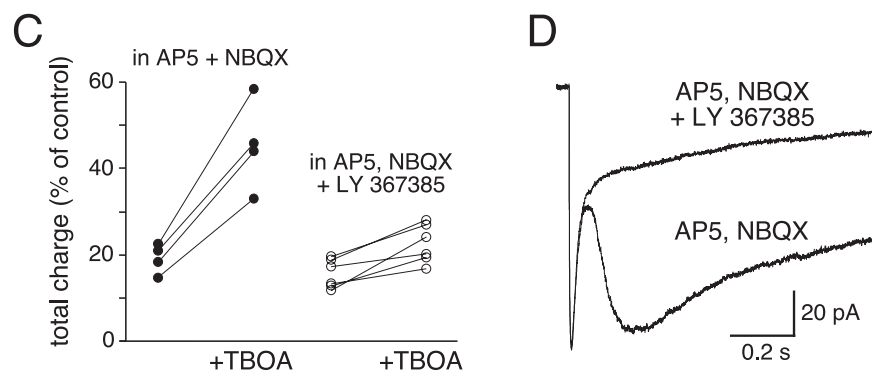

Figure 6. Glomerular astrocytes detect the glutamate released at olfactory nerve terminals. $\boldsymbol{A}$, The initial fast component of the astrocyte current recorded in the presence of AP-5 and NBQX (black trace) was blocked by TBOA ( $50 \mu \mathrm{m}$, see inset), consistent with a synaptic transporter current. However, TBOA also facilitated the slow potassium component of the astrocyte response (compare gray and black traces). $\boldsymbol{B}$, The astrocyte response still contained a transporter current (inset) when $\mathrm{mGluR1}$ receptors were blocked with LY367385 $(25-50 \mu \mathrm{M})$, but the potentiation of the $\mathrm{K}^{+}$current by TBOA was much less prominent. $C$, The effects of TBOA are shown as a percentage of the total charge measured in the absence of receptor or transporter blockers. $\boldsymbol{D}$, The mGluR1 blocker LY367385 had no effect on the synaptic transporter current, but it reduced the astrocyte potassium current. In $\boldsymbol{A}, \boldsymbol{B}$, and $\boldsymbol{D}, \mathrm{AP}-5$ $(150 \mu \mathrm{M})$ and NBQX $(20 \mu \mathrm{M})$ were present throughout the recording. LY, LY367385.

The potentiation by TBOA of the mGluR1-mediated EPSP generated in mitral cells was also reflected in astrocyte recordings. In the presence of AP-5 and NBQX, TBOA enhanced the slow $\mathrm{K}^{+}$ component of the astrocyte response (Fig. $6 A, C$ ). This enhancement was occluded by LY367385 $(n=7)$ (Fig. $6 B, C)$. These data provide additional evidence that the $\mathrm{K}^{+}$component of the astrocyte response is a sensitive indicator of intraglomerular mitral/ tufted cell activity.

\section{Astrocytes detect the glutamate released at olfactory neuron terminals}

Morphological data suggest that astrocytes surround dendrodendritic synapses in dendritic compartments but are absent or less prominent at axodendritic synapses between olfactory nerve terminals and mitral or tufted cells (Chao et al., 1997; Kasowski et al., 1999). Thus, we initially hypothesized that the astrocytes would sense transmitter release only at dendrodendritic synapses. However, a TBOA-sensitive transient current remained when dendrodendritic synapses were blocked by AP-5 plus NBQX (Fig. $6 A$, inset) $\left(n=16\right.$ in rats, $25^{\circ} \mathrm{C} ; n=12$ in mice, $\left.33-36^{\circ} \mathrm{C}\right)$. This transporter current was also present in AP-5, NBQX, and LY367385 (Fig. 6B, inset), conditions that completely abolished mitral and tufted cell activation (Fig. 5A). Thus, glomerular astrocytes can detect glutamate release in the axonal compartment. The amplitude of the transporter current in AP-5 plus NBQX was not reduced further by LY367385 $(p<0.3 ; n=$ 7) (Fig. $6 D$ ), suggesting that the mGluR1 EPSP remaining in mitral/tufted cells in the presence of AP-5 and NBQX (Fig. $5 A$ ) is not sufficient to evoke detectable release of glutamate from mitral/tufted cell dendrites.

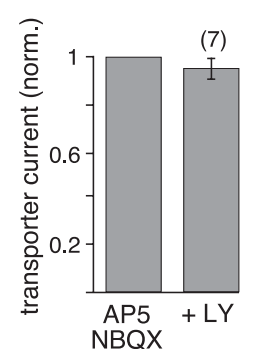

Astrocytes detect the glutamate released at olfactory neuron terminals and at mitral/tufted cell dendrites

To determine whether astrocytes detect glutamate released at dendrodendritic synapses, we examined the effect of glutamate receptor antagonists on the transporter current isolated in the presence of external $\mathrm{Ba}^{2+}$ (Fig. 7A). By preventing mitral/tufted cell activation, GluR blockers should selectively block the dendrodendritic component of the transporter current mediated by glutamate released from mitral/tufted cells but leave unaffected the axodendritic component mediated by glutamate released from olfactory neurons. In rat slices, AP-5 plus NBQX reduced the transporter current by $39 \pm 5.2 \%(n=9)$ but had no effect in three other cells. Similar results were obtained with AP-5 plus NBQX plus LY367385 in mouse slices (35.6 $\pm 6.9 \%$ inhibition; $n=8)$. Thus most astrocytes detect glutamate release at both olfactory nerve terminals and mitral/ tufted cell dendrites.

In cells exhibiting sufficiently large transporter currents, we examined the dendrodendritic transporter current by subtracting the axodendritic GluT current remaining in glutamate receptor antagonists from the control transporter current (Fig. 7B). In barium, the dendrodendritic transporter current was slightly delayed compared with the axodendritic transporter current $(1.9 \pm 0.7$ $\mathrm{ms}$ between the onset of the dendrodendritic and axodendritic transporter currents, $n=7$ cells in rats; $0.8 \pm 0.3 \mathrm{~ms}$ in mice, $n=$ 5 ), indicating that glutamate is released from mitral/tufted cells shortly after their activation by the olfactory nerve input. The dendrodendritic transporter current also had slower kinetics (10-90\% rise time, $8.4 \pm 0.9 \mathrm{~ms}$; decay time, $26.6 \pm 1.7 \mathrm{~ms}$; half-width, $31.7 \pm 1.1 \mathrm{~ms})$ than the axodendritic transporter current (10-90\% rise time, $4.2 \pm 0.4 \mathrm{~ms}$; decay time, $13.9 \pm 1.4$ ms; half-width, $17.3 \pm 1.6 \mathrm{~ms} ; n=7$ cells in rat slices) (Fig. $7 C$ ).

\section{Discussion}

Removal of $\mathrm{K}^{+}$from the extracellular space (Amédée et al., 1997; Kofuji and Newman, 2004) and clearance of glutamate from the synaptic cleft (Danbolt, 2001) are two well known functions of astrocytes in the brain. Both mechanisms produce currents in glial cells that are caused by and reflect neuronal activity, as illustrated by our recordings from olfactory bulb astrocytes. Similar to astrocytes in the hippocampus (Bushong et al., 2002), olfactory bulb astrocytes exhibit a very dense spongiform arborization, a morphology that results in an intimate relationship with neurons and synapses and the ability to sense neuronal activity in compartments within the neuropil. Glomerular astrocytes project their ramifications into a single glomerulus, an anatomical specialization considered to be the functional unit for odor processing. Moreover, mitral cells projecting to the same glomerulus show highly correlated activity (Carlson et al., 2000; Schoppa and Westbrook, 2001, 2002). Therefore, currents produced by $\mathrm{K}^{+}$ and glutamate uptake in glomerular astrocytes report the ensemble activity of a group of neurons behaving as a single unit. 


\section{Potassium accumulation in olfactory bulb glomeruli}

A single action potential may produce a transient increase of $\sim 1 \mathrm{~mm}$ extracellular $\mathrm{K}^{+}$(Walz, 2000). In the bulb, $\mathrm{K}^{+}$sensitive electrodes have revealed that potassium can reach 7-8 $\mathrm{mm}$ in the glomerular layer in response to a single olfactory nerve stimulation (Jahr and Nicoll, 1981; Khayari et al., 1988). This $\mathrm{K}^{+}$accumulation is reflected as a long-lasting and $\mathrm{Ba}^{2+}$-sensitive current in glomerular astrocytes, caused by $\mathrm{K}^{+}$permeability of $\mathrm{Ba}^{2+}$-sensitive IRK channels. The similarity between the astrocyte and mitral/tufted cell responses to olfactory nerve stimulation suggests that mitral/tufted cells are the primary source of the $\mathrm{K}^{+}$. This is not surprising, because mitral/tufted cells have a depolarized resting potential $(-55 /$ $-60 \mathrm{mV}$ ) (Schoppa and Westbrook, 2001) and generate long-lasting EPSPs in response to olfactory nerve stimulation. The highly correlated activity of mitral/ tufted cells within a glomerulus will also enhance efflux of $\mathrm{K}^{+}$into the extracellular space.

Astrocytes are thought to use IRK channels to remove $\mathrm{K}^{+}$from regions with high extracellular $\mathrm{K}^{+}$and release it to regions with low $\mathrm{K}^{+}$, a mechanism known as spatial buffering or siphoning of $\mathrm{K}^{+}$ (Karwoski et al., 1989; Amédée et al., 1997;

Kofuji and Newman, 2004). In the retina, Kir4.1 channels are the main channels involved in the regulation of external $\mathrm{K}^{+}$(Kofuji et al., 2000). Kir4.1 is also highly expressed in glomerular astrocytes, particularly in processes wrapping synapses and blood vessels (Higashi et al., 2001). As proposed by Higashi et al. (2001), $\mathrm{K}^{+}$could be siphoned from the glomerular neuropil by glial Kir4.1 channels and released into blood vessels.

A recent modeling study suggested that the envelope of astrocytes around each glomerulus should reduce $\mathrm{K}^{+}$diffusion and thus limit interglomerular interactions (Goriely et al., 2002). The morphology of GFAP-GFP and dye-loaded astrocytes supports a glomerular-specific distribution of astrocytes. Likewise, if we moved the stimulating electrode laterally by $50-100 \mu \mathrm{m}$, the glial potassium response diminished markedly (data not shown), consistent with limitation of extracellular $\mathrm{K}^{+}$accumulation within glomeruli. Dual astrocyte recording in adjacent glomeruli would be required to definitively demonstrate the lack of interglomerular interaction, but this proved extremely difficult in our experience.

It is not clear whether removal of $\mathrm{K}^{+}$is complete or fast enough to prevent intraglomerular excitation of neuronal processes. Murphy and Isaacson (2003) reported recently that a mild exogenous increase in extracellular $\mathrm{K}^{+}(5-7.5 \mathrm{~mm})$ can depolarize olfactory nerve terminals and reduce their excitability. Thus, as proposed by Jahr and Nicoll (1981), depolarization of olfactory afferent terminals by high external $\mathrm{K}^{+}$caused by mitral/tufted cell activity may contribute to the pronounced paired-pulse depression at axodendritic synapses. Consistent with this hypothesis, we found that transporter currents evoked by two OSN stimuli at $100 \mathrm{~ms}$ intervals were not depressed in the presence of
NBQX, AP-5, and LY367385 [paired-pulse ratio (PPR) was $95.7 \pm 2.9 \% ; n=7$; data not shown]. This result is in contrast to the pronounced paired-pulse depression in tufted or periglomerular cells (PPR <50\%) (Ennis et al., 2001; Murphy et al., 2004). However, other factors may also explain the absence of depression observed when astrocytes were used to monitor glutamate release from olfactory nerve terminals. First, dopamine and GABA, two potent retrograde inhibitors of presynaptic glutamate release (Aroniadou-Anderjaska et al., 2000; Ennis et al., 2001), are no longer released when excitatory transmission is blocked. Second, transporter currents were recorded in the presence of $\mathrm{Ba}^{2+}$ that may affect the properties of glutamate release from olfactory terminals.

\section{Astrocytes as detectors of glutamate release}

The glial transporter current evoked in glomerular astrocytes was mediated by glutamate release at both axodendritic and dendrodendritic synapses. In the presence of $\mathrm{Ba}^{2+}$, most of the glutamate detected by a glomerular astrocyte was released from OSN terminals. This result by itself is not surprising, because olfactory sensory neurons release glutamate with high probability (Murphy et al., 2004) and axodendritic synapses vastly outnumber dendrodendritic synapses in glomeruli (Kasowski et al., 1999). However, our estimate must be taken with caution, because $\mathrm{Ba}^{2+}$ directly depolarizes mitral and tufted cells (data not shown) and may affect the excitability of olfactory nerve terminals as well. Thus, the presence of $\mathrm{Ba}^{2+}$ may distort the relative contribution of the two synaptic compartments to astrocytic transporter current.

The transporter current mediated by glutamate released from 
mitral/tufted cell dendrites exhibited slower kinetics than the component mediated by glutamate release from olfactory axons. Asynchrony of glutamate release from mitral/tufted cells is a likely factor contributing to the slower time course. Although $\mathrm{Ba}^{2+}$ could alter the time course of glutamate release, asynchrony of glutamate release from mitral/tufted cells has been reported recently. Specifically, some periglomerular neurons receiving inputs from mitral/tufted cells respond to olfactory nerve stimulation with a barrage of EPSC of variable latency (Hayar et al., 2004). In contrast, in periglomerular cells that receive monosynaptic olfactory nerve input, afferent stimulation evokes a shortlatency, monophasic EPSC (Ennis et al., 2001; Hayar et al., 2004). This result is consistent with synchronous release of glutamate as suggested by the fast kinetic of the axodendritic transporter current.

\section{Anatomical and functional compartmentalization of olfactory glomeruli}

The anatomical organization of olfactory glomeruli has been carefully examined with immunohistochemistry and electron microscopy. These studies indicate that the axodendritic and dendrodendritic synapses are spatially segregated in different glomerular subcompartments (Chao et al., 1997; Kosaka et al., 1997; Kasowski et al., 1999; Kim and Greer, 2000). Some reports have further argued that astrocyte processes delineate the subcompartments, enveloping some but not all dendrodendritic synapses, whereas they seem to be excluded from axodendritic synapses (Chao et al., 1997; Kasowski et al., 1999). This organization might suggest that astrocytes detect glutamate release only from mitral/ tufted cell dendrites. In contrast, our results indicate that glomerular astrocytes also detect glutamate release from olfactory axon terminals. The kinetics of the synaptically evoked axodendritic transporter currents were similar to those recorded in the hippocampus (Bergles and Jahr, 1997), where astrocyte processes are closely apposed to synapses (Ventura and Harris, 1999). This might suggest that astrocyte processes are located close to axodendritic synapses. However, as in the hippocampus, where the glial coverage of synapses is variable (Ventura and Harris, 1999), astrocytic processes may not be present at all synapses. This could explain why glia-ensheathed axodendritic synapses were not seen in some studies (Chao et al., 1997; Kasowski et al., 1999) but reported in others (Higashi et al., 2001). Alternatively astrocyte processes might be located between axodendritic and dendrodendritic synapses, thereby providing a diffusional barrier. If the two surfaces of this barrier are covered with GluTs, astrocytes could detect glutamate released from both synapses.

Although mGluR1 has been shown to regulate the excitability of mitral cells (Heinbockel et al., 2004), our results provide the first evidence that mitral/tufted cell mGluR1s are synaptically activated by glutamate released at olfactory neuron terminals, even with single stimuli. Activation of mGluR1 was limited by glutamate transporters. Thus glial GluTs at axodendritic synapses could regulate olfactory bulb processing by controlling mGluR1 synaptic activation. The presence of glial GluTs at axodendritic synapses may also reinforce synaptic compartmentalization within glomeruli. Indeed, several properties of axodendritic synapses suggest that large amounts of glutamate are released in the axonal compartments. First, several olfactory neuron terminals form clusters of boutons onto mitral/tufted cell dendrites, leaving no apparent space between boutons for astrocytic processes [Kasowski et al. (1999), their Figs. 2, 4]. Second, the probability of transmitter release is high at olfactory afferent terminals (Murphy et al., 2004). These properties are a recipe for spillover of glutamate at axodendritic synapses. However, astrocytes GluTs in the axonal compartments may serve to limit glutamate diffusion and prevent cross talk between axodendritic and dendrodendritic synapses.

\section{References}

Amédée T, Robert A, Coles JA (1997) Potassium homeostasis and glial energy metabolism. Glia 21:46-55.

Anwyl R (1999) Metabotropic glutamate receptors: electrophysiological properties and role in plasticity. Brain Res Brain Res Rev 29:83-120.

Aroniadou-Anderjaska V, Zhou FM, Priest CA, Ennis M, Shipley MT (2000) Tonic and synaptically evoked presynaptic inhibition of sensory input to the rat olfactory bulb via $\mathrm{GABA}_{\mathrm{B}}$ heteroreceptors. J Neurophysiol 84:1194-1203.

Bailey MS, Shipley MT (1993) Astrocyte subtypes in the rat olfactory bulb: morphological heterogeneity and differential laminar distribution. J Comp Neurol 328:501-526.

Bergles DE, Jahr CE (1997) Synaptic activation of glutamate transporters in hippocampal astrocytes. Neuron 19:1297-1308.

Bridges RJ, Kavanaugh MP, Chamberlin AR (1999) A pharmacological review of competitive inhibitors and substrates of high-affinity, sodiumdependent glutamate transport in the central nervous system. Curr Pharm Des 5:363-379.

Buck LB (2000) The molecular architecture of odor and pheromone sensing in mammals. Cell 100:611-618.

Bushong EA, Martone ME, Jones YZ, Ellisman MH (2002) Protoplasmic astrocytes in CA1 stratum radiatum occupy separate anatomical domains. J Neurosci 22:183-192.

Carlson GC, Shipley MT, Keller A (2000) Long-lasting depolarizations in mitral cells of the rat olfactory bulb. J Neurosci 20:2011-2021.

Chao TI, Kasa P, Wolff JR (1997) Distribution of astroglia in glomeruli of the rat main olfactory bulb: exclusion from the sensory subcompartment of neuropil. J Comp Neurol 388:191-210.

Chen WR, Shepherd GM (1997) Membrane and synaptic properties of mitral cells in slices of rat olfactory bulb. Brain Res 745:189-196.

Danbolt NC (2001) Glutamate uptake. Prog Neurobiol 65:1-105.

Ennis M, Zhou FM, Ciombor KJ, Aroniadou-Anderjaska V, Hayar A, Borrelli E, Zimmer LA, Margolis F, Shipley MT (2001) Dopamine D2 receptormediated presynaptic inhibition of olfactory nerve terminals. J Neurophysiol 86:2986-2997.

Friedrich RW, Korsching SI (1998) Chemotopic, combinatorial, and noncombinatorial odorant representations in the olfactory bulb revealed using a voltage-sensitive axon tracer. J Neurosci 18:9977-9988.

Goriely AR, Secomb TW, Tolbert LP (2002) Effect of the glial envelope on extracellular $\mathrm{K}(+)$ diffusion in olfactory glomeruli. J Neurophysiol $87: 1712-1722$.

Hayar A, Karnup S, Ennis M, Shipley MT (2004) External tufted cells: excitatory element that coordinates glomerular activity. J Neurosci 24:6676-6685.

Heinbockel T, Hayward P, Conquet F, Ennis M (2004) Regulation of main olfactory bulb mitral cell excitability by metabotropic glutamate receptor mGluR1. J Neurophysiol 92:3085-3096.

Higashi K, Fujita A, Inanobe A, Tanemoto M, Doi K, Kubo T, Kurachi Y (2001) An inwardly rectifying $\mathrm{K}(+)$ channel, Kir4.1, expressed in astrocytes surrounds synapses and blood vessels in brain. Am J Physiol Cell Physiol 281:C922-C931.

Jahr CE, Nicoll RA (1981) Primary afferent depolarization in the in vitro frog olfactory bulb. J Physiol (Lond) 318:375-384.

Karwoski CJ, Lu HK, Newman EA (1989) Spatial buffering of light-evoked potassium increases by retinal Muller (glial) cells. Science 244:578-580.

Kasowski HJ, Kim H, Greer CA (1999) Compartmental organization of the olfactory bulb glomerulus. J Comp Neurol 407:261-274.

Khayari A, Math F, Davrainville JL (1988) Electrical stimulation of primary olfactory nerve induces two types of variations in the extracellular potassium activity within the glomerulus of the rat olfactory bulb in vivo. Brain Res 457:188-191.

Kim H, Greer CA (2000) The emergence of compartmental organization in olfactory bulb glomeruli during postnatal development. J Comp Neurol 422:297-311.

Kofuji P, Newman EA (2004) Potassium buffering in the central nervous system. Neuroscience 129:1045-1056.

Kofuji P, Ceelen P, Zahs KR, Surbeck LW, Lester HA, Newman EA (2000) 
Genetic inactivation of an inwardly rectifying potassium channel (Kir4.1 subunit) in mice: phenotypic impact in retina. J Neurosci 20:5733-5740.

Kosaka K, Toida K, Margolis FL, Kosaka T (1997) Chemically defined neuron groups and their subpopulations in the glomerular layer of the rat main olfactory bulb. II. Prominent differences in the intraglomerular dendritic arborization and their relationship to olfactory nerve terminals. Neuroscience 76:775-786.

Kosaka K, Toida K, Aika Y, Kosaka T (1998) How simple is the organization of the olfactory glomerulus?: the heterogeneity of so-called periglomerular cells. Neurosci Res 30:101-110.

Matsui K, Jahr CE (2003) Ectopic release of synaptic vesicles. Neuron 40:1173-1183.

Mombaerts P, Wang F, Dulac C, Chao SK, Nemes A, Mendelsohn M, Edmondson J, Axel R (1996) Visualizing an olfactory sensory map. Cell 87:675-686.

Murphy GJ, Isaacson JS (2003) Presynaptic cyclic nucleotide-gated ion channels modulate neurotransmission in the mammalian olfactory bulb. Neuron 37:639-647.

Murphy GJ, Glickfeld LL, Balsen Z, Isaacson JS (2004) Sensory neuron signaling to the brain: properties of transmitter release from olfactory nerve terminals. J Neurosci 24:3023-3030.

Newman EA (1993) Inward-rectifying potassium channels in retinal glial (Müller) cells. J Neurosci 13:3333-3345.

Orkand RK, Nicholls JG, Kuffler SW (1966) Effect of nerve impulses on the membrane potential of glial cells in the central nervous system on amphibia. J Neurophysiol 29:788-806.

Pinching AJ, Powell TPS (1971) The neuropil of the glomeruli of the olfactory bulb. J Cell Sci 9:347-377.

Ressler KJ, Sullivan SL, Buck LB (1994) Information coding in the olfactory system: evidence for a stereotyped and highly organized epitope map in the olfactory bulb. Cell 79:1245-1255.

Schoppa NE, Urban NN (2003) Dendritic processing within olfactory bulb circuits. Trends Neurosci 9:501-506.

Schoppa NE, Westbrook GL (2001) Glomerulus-specific synchronization of mitral cells in the olfactory bulb. Neuron 31:639-651.

Schoppa NE, Westbrook GL (2002) AMPA autoreceptors drive correlated spiking in olfactory bulb glomeruli. Nat Neurosci 5:1194-1202.

Schoppa NE, Kinzie JM, Sahara Y, Segerson TP, Westbrook GL (1998) Dendrodendritic inhibition in the olfactory bulb is driven by NMDA receptors. J Neurosci 18:6790-6802.

Utsumi M, Ohno K, Onchi H, Sato K, Tohyama M (2001) Differential expression patterns of three glutamate transporters (GLAST, GLT1 and EAAC1) in the rat main olfactory bulb. Brain Res Mol Brain Res 92:1-11.

Valverde F, Lopez-Mascaraque L (1991) Neuroglial arrangements in the olfactory glomeruli of the hedgehog. J Comp Neurol 307:658-674.

van den Pol AN (1995) Presynaptic metabotropic glutamate receptors in adult and developing neurons: autoexcitation in the olfactory bulb. J Comp Neurol 359:253-271.

Vassar R, Chao SK, Sitcheran R, Nunez JM, Vosshall LB, Axel R (1994) Topographic organization of sensory projections to the olfactory bulb. Cell 79:981-991.

Ventura R, Harris KM (1999) Three-dimensional relationships between hippocampal synapses and astrocytes. J Neurosci 19:6897-6906.

Walz W (2000) Role of astrocytes in the clearance of excess extracellular potassium. Neurochem Int 36:291-300.

Zhuo L, Sun B, Zhang CL, Fine A, Chiu SY, Messing A (1997) Live astrocytes visualized by green fluorescent protein in transgenic mice. Dev Biol 187: $36-42$. 